\title{
Consequências jurídicas às corporações pela não observância das diretrizes de saúde e segurança do trabalho na prestação de serviços terceirizados
}

\section{Legal consequences for corporations for non-compliance with occupational health and safety guidelines in the provision of outsourced services}

\author{
Recebimento: 10/03/2021 - Aceite: 24/04/2021 - Publicação: 1/09/2021 \\ Processo de Avaliação: Double Blind Review
}

\author{
Maria de Fatima Nentes Panaino \\ Engenheira de Produção, \\ Acadêmica do curso Lato-Sensu de Engenharia de Segurança do Trabalho do Centro \\ Universitário Eniac, Brasil \\ panaino.fatima@gmail.com \\ http://orcid.org/0000-0001-8145-1687
}

\author{
Renato de Brito Sanchez \\ Professor Doutor e Pesquisador dos cursos de Engenharia no Centro Universitário Eniac e na \\ Universidade Santo Amaro (Unisa), Brasil \\ Pesquisador da Universidade de Mogi das Cruzes (UMC), Núcleo de Pesquisas Tecnológicas \\ (NPT - LAVITA), Brasil \\ renatobritosanchez@gmail.com \\ http://orcid.org/0000-0002-8335-2540
}

\section{RESUMO}

Evidenciando que praticamente em toda organização existe a necessidade de contratação de mão-de-obra de Prestadores de Serviço Terceirizados, ainda mais com falta de mão-de-obra ou não contemplar especialistas em todas as áreas e tal cenário requer critérios e procedimentos que estabeleçam diretrizes, atitudes e comportamentos a serem adotados no que tange à contratação e gestão de empresas prestadoras de serviços e de seus funcionários. Sendo assim, objetiva-se neste trabalho demonstrar que definir as competências e as responsabilidades dos envolvidos nos processos de contração e gestão das prestadoras de serviço tornou-se fundamental para garantir a Segurança e Saúde dos terceirizados que necessitem realizar atividades nas dependências da organização. Sendo utilizada como metodologia, a aplicação de um questionário incisivo e objetivo, consegue-se uma visão mais estreita de como é o dia a dia dos profissionais que atuam diretamente nessas contratações e 
como são suas ações perante os problemas que podem decorrer nesses casos. Com isso, o presente trabalho consegue contribuir com uma conclusão estatística das consequências, sobretudo, dos impactos decorrentes a processos trabalhistas envolvendo mão-de-obra de Prestadores de Serviços Terceirizados que a organização está sujeita, ainda mais naquelas alheias total ou parcialmente às diretrizes na Segurança e Saúde do Trabalho.

Palavras-chave: organização, prestadores de serviço terceirizados, saúde e segurança do trabalho, processos trabalhistas

\section{ABSTRACT}

Evidencing that practically in every organization there is a need to hire labor from Outsourced Service Providers, especially with a lack of manpower or not having specialists in all areas, and this scenario requires criteria and procedures that establish guidelines, attitudes and behaviors to be adopted with regard to the hiring and management of service providers and their employees. Therefore, the objective of this work is to demonstrate that defining the competencies and responsibilities of those involved in the contracting and management processes of service providers has become essential to ensure the Safety and Health of outsourced workers who need to carry out activities on the organization's premises. Being used as a methodology, the application of an incisive and objective questionnaire, it is possible to get a closer view of the day-to-day life of the professionals who work directly in these hires and how their actions are in the face of the problems that may arise in these cases. . With this, the present work is able to contribute with a statistical conclusion of the consequences, above all, of the impacts resulting to labor processes involving labor of Outsourced Service Providers that the organization is subject, even more in those that are totally or partially oblivious to the guidelines in the Occupational Health and Safety.

Keywords: organization, outsourced service providers, health and safety, labor proceedings 


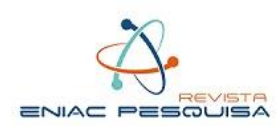

\section{INTRODUÇÃO}

Desde o começo das relações de trabalho, no período pós Revolução Industrial, o trabalhador e o empregador possuíam visões distintas, consequentemente, cada qual focado na sua necessidade individual. Todavia, atualmente, entende-se que ao trabalhador empregado lhe cabe o cumprimento de seus deveres aos quais ele foi contratado, e ao empregador lhe cabe proporcionar as devidas condições de trabalho com a devida segurança, de modo a preservar a integridade física do trabalhador, bem como, garantir a saúde dele. Não obstante, a extensão dessa condição aos colaboradores terceirizados, onde a não observância dos procedimentos e diretrizes na prestação de serviços terceirizados pelas corporações concorre ao grande risco de resultar em processos trabalhistas.

Em primeiro lugar, a resistência em integrar uma gestão eficaz de Prestadores de Serviços Terceirizados à cultura da organização vem resultando em altos índices de acidentes e doenças do trabalho dentre eles, uma vez que, a contratação desses prestadores geralmente se dá através de agências, que em grande parte, não cumprem com todas as Leis, Normas e Procedimentos, isso se dá por conta da concorrência e a necessidade de sobreviver a um mercado extremamente competitivo. Desse modo, a busca incessantemente por reduções de custos desses tipos de Mão-de-Obra, passando assim, a priorizar a execução do serviço a qual está sendo contratada, e não em como o serviço será executado em relação ao cumprimento das normas de Segurança e Saúde do Trabalhador.

É importante salientar que a segurança do trabalho não se limita somente a ditar normas, regras, procedimentos e diretrizes, sendo elas classificadas como medidas técnicas ou administrativas. As ações que possibilitem os prestadores entenderem a importância das medidas e da cultura da organização a qual eles estão inseridos fazem toda a diferença, pois assim, eles saberão exatamente o porquê é necessário seguir as diretrizes fixadas. De nada adianta impor diversas medidas de segurança, se os próprios prestadores não entendem como aplicá-las efetivamente, e no final ele é prejudicado: lesão, doença ocupacional, afastamento das atividades laborais, impacto financeiro, ou pior, óbito. Dessa forma, toda cadeia envolvida é impactada, familiares, demais trabalhadores da corporação, que ficam suscetíveis a impactos psíquicos e sociais, e danos à imagem da corporação e os consequentes custos monetários.

O processo de contratação de Prestadores de Serviço Terceirizados demonstra, em sua maioria, uma fragilidade na identificação das estreitas interfaces entre o Contratante 


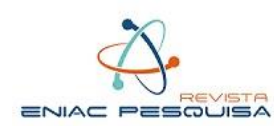

(Organização) e a Contratada (Empresas Terceiras), onde é evidente a dificuldade do entendimento dos interessados em perceberem que são interdependentes e complementares, no que diz respeito às responsabilidades: à Saúde e Segurança Ocupacional, à Ética e às questões Cíveis e Criminais dos trabalhadores.

Carvalho (2015) descreve que, na década de 50, a terceirização chegou ao Brasil através das multinacionais. $\mathrm{O}$ autor destaca que "de fato, ao terceirizar atividades, as empresas logram libertar-se de certas obrigações trabalhistas, tais como, equiparação salarial por funções semelhantes e benefícios previstos em normas coletivas".

Com grande rapidez, observou-se uma grande procura por esse tipo de contratação, sobretudo, pelo objetivo de desonerar a folha salarial, devido aos encargos trabalhistas desses trabalhadores terceirizados serem menores e pela relativa falta de responsabilidade pelo mesmo. Entretanto, com o aumento da população de colaboradores terceiros CNPJ, percebeuse que eles eram tratados de modo diferenciado dos colaboradores CLT: sem os mesmos direitos, o devido cuidado na qualificação, habilitação, treinamentos, com a falta de supervisão e responsabilidade no que tange a entrega de EPIs e inclusão às normas internas.

Para a corporação contratante era simples, exigia-se da agência contratada a reposição desses colaboradores e se reiniciava o ciclo, com as mesmas condições. Tais situações só foram aumentando consideravelmente os números negativos e assim chamando a atenção das autoridades públicas que criaram leis que limitavam esses tipos de contratações e exigiram de quem os contratassem, estendessem os direitos, condições e controles deles.

Cabe salientar que trabalhos terceirizados, envolve-se também o contratado direto, cuja contratação requer os mesmos cuidados na forma e ênfases nos direitos e deveres, pois esses colaboradores também são corresponsabilidades da empresa contratante. Assim sendo, as aplicações da legislação prevista nas Consolidações das Leis do Trabalho devem ser levadas em considerações aos prestadores contratados como pessoa jurídica, por exemplo.

Por conseguinte, a Segurança do Trabalho possui conceitos bem mais amplos do que sua configuração intitula, como principal objetivo a saúde e segurança dos trabalhadores, sendo correto ampliar a visão referente a essa questão em uma magnitude macro, onde cabe ampliar os conceitos para questões jurídicas. 


\section{REFERENCIAL TEÓRICO}

\section{1 período pré-industrial}

"Na sociedade pré-industrial não há um sistema de normas jurídicas de direito do trabalho. Predominou a escravidão, que fez do homem simplesmente uma coisa. O escravo não tinha, pela sua condição, direitos trabalhistas.” (Nascimento, 2002, p.39).

Nesse chamado período de escravidão, o ser-humano era tratado sem nenhuma dignidade, sendo obrigado a trabalhar em condições de trabalho insalubres, perigosas e sema devida remuneração.

Ao tratarmos do termo trabalho em seu contexto mundial, veremos que ele apresenta diferentes fases, considerando-se desde o trabalho escravo - escravidão - ao sistema de servidões, [...] e à Revolução Industrial, quando surge o Direito Laboral. (2007, p. 37).

A segurança do trabalho e saúde ocupacional, não devem ser estigmatizadas com preceitos estáticos que demandam ações pontuações. Ficando evidente que tal preceito está em constante evolução, seja para atender pejorativas jurídicas legais, normas e leis, obviamente o envolvimento dos trabalhadores com os mediadores "sindicatos", surtem efeitos positivos e negativos nesse processo de evolução.

\subsection{O início das normas regulamentadoras no brasil e suas aplicabilidades}

No Brasil em 08 de junho de 1978, o Ministério do Trabalho expediu a portaria $\mathrm{n}^{\circ}$ 3.214, composta inicialmente de 28 Normas Regulamentadoras (NRs), relativas à Segurança e Medicina do Trabalho (sendo, atualmente, composta por 37 NRs), que buscam ter interação com todos os processos produtivos no Brasil.

A análise foi realizada conforme itens estabelecidos em NRs, Portaria n. ${ }^{\circ} 3.214$, de 08 de junho de 1978, e última alteração da Portaria da Secretaria de Inspeção do Trabalho (SIT) n. ${ }^{\circ}$ 247, de 12 de julho de 2011, e Consolidação das Leis do Trabalho (CLT) estabelecida pelo Decreto-Lei n. ${ }^{\circ} 5.452$, de $1^{\circ}$ de maio de 1943 , que reuniu e unificou a legislação trabalhista existente à época no país. Esta obra apresenta a CLT já com as modificações promovidas pela reforma trabalhista de 2017, consubstanciada na Lei n. ${ }^{\circ}$ 13.467, de 13 de julho de 2017, bem como com as mudanças determinadas pela Medida Provisória n. ${ }^{\circ}$ 808, de 2017, os Art. 163, Art. 164 e Art. 165, foram utilizados neste estudo de caso a Lei $\mathrm{n}^{\circ} 8.213$ de 24 de julho de 1991, em seu artigo 19. 


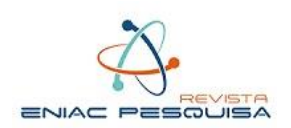

Destas, temos a nova redação da NR $n^{\circ} 01$ como a norma que possui as diretrizes de Disposições Gerais e Gerenciamento de Ricos Ocupacionais.

1.5.8.2 O PGR da empresa contratante poderá incluir as medidas de prevenção para as empresas contratadas para prestação de serviços que atuem em suas dependências ou local previamente convencionado em contrato ou referenciar os programas d contratadas. (Redação dada pela Portaria SEPRT n. ${ }^{\circ}$ 6.730, de 09/03/20).

As normas regulamentadoras dispõem sobre as relações que devem existir entre os trabalhadores e seu ambiente de trabalho, seja essa relação abrangente as empresas de prestação de serviços públicos a terceiros.

A Norma Regulamentadora ${ }^{\circ} 7$ (NR nº7) - Programa de Controle Médico de Saúde Ocupacional - PCMSO, determina a obrigatoriedade da elaboração e implementação desse programa, como uma série de ações que visa a promoção e preservação da saúde dos trabalhadores.

7.1.3 Caberá à empresa contratante de mão-de-obra prestadora de serviços informar à empresa contratada dos riscos existentes e auxiliar na elaboração e implementação do PCMSO nos locais de trabalho onde os serviços estão sendo prestados. (Alterado pela Portaria SSST n. ${ }^{\circ} 8$, de 05 de maio de 1996).

Diante das diversidades do ambiente fabril, um fator que permanece em evidência é a importância cumprimento das Leis, Normas e Procedimentos de Saúde e Segurança instituídos pelos órgãos competentes que visa a proteção do trabalhador e sucessivamente gera benefícios ao empregador e consequentemente a toda sociedade, uma vez que não devolve ao meio, trabalhadores lesionados ou doentes, resultado, esse, alcançado através do desenvolvimento de suas atividades laborais.

Temos que estabelece a NR n 9 - Programa de Riscos Ambientais, no item "9.1.1 Esta Norma Regulamentadora - NR estabelece a obrigatoriedade da elaboração e implementação, por parte de todos os empregadores e instituições que admitam trabalhadores como empregados, do Programa de Prevenção de Riscos Ambientais - PPRA”. 


\subsection{Reforma trabalhista}

Em 2017 houve a reforma trabalhista no Brasil, a Lei $n^{\circ}$ 13.467/2017, contemplando os direitos de as empresas utilizarem a terceirização em qualquer atividade.

Art. $4^{\circ}$-A. Considera-se prestação de serviços a terceiros a transferência feita pela contratante da execução de quaisquer de suas atividades, inclusive sua atividade principal, à pessoa jurídica de direito privado prestadora de serviços que possua capacidade econômica compatível com a sua execução. (Redação dada pela Lei no 13.467 , de 2017).

A intenção em se integrar a organização à prestação de serviços a terceiros, é deter-se a uma Mão-de-Obra especializada, uma vez que seus trabalhadores não possuam tais competências.

\subsection{Condições adversas}

Tendo em vista essas informações, a problemática escolhida para estudo foi demonstrar a fragilidades nos processos de gestão e contratação de Prestação de Serviços Terceirizados e o quão despreparadas estão as empresas terceirizadas e pessoas jurídicas, quanto ao conhecimento do que lhe são aplicáveis no parâmetro legal. Cabe ainda salientar, que a pressão que o responsável pela contratação desse tipo de mão-de-obra sofre dentro da corporação, e a falta de conhecimento quanto às Leis, Normas e Procedimentos necessários, são fatores que devem ser levados em consideração. Tais situações demonstram que em sua maioria os tomadores desse tipo de mão-de-obra não integram em seus procedimentos de contratação, itens relacionados à Saúde e Segurança do Trabalho, tampouco preveem os impactos referente à ética e questões cíveis, criminais e exposição aos possíveis processos trabalhistas, que a organização pode vir a sofrer, caso não as atenda.

Ressalta-se que a contratação deste tipo de mão-de-obra quase sempre é determinada pelo valor do trabalho a ser realizado, e não condizente aos processos implementados para o cumprimento das leis, normas e procedimentos. Isso resulta em consequências imensuráveis para organização, que em grande parte delas, a diretoria não está ciente do quão exposta está a organização, motivo esse de não terem aprofundamento das informações num nível que permita fazer um estudo de causa e impactos. Sendo assim, é imprescindível a alta direção ter conhecimento das consequências de um acidente ou doença ocupacional adquirida na organização, sobretudo aos trabalhadores terceirizados e negligenciar esse fato resulta em 


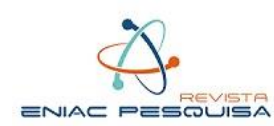

processos trabalhistas, que poderiam ser evitados com o envolvimento de uma equipe multidisciplinar de profissionais tais como: engenheiros de segurança do trabalho, técnico de segurança do trabalho, médico do trabalho e advogados que obtenham um acesso direto a alta direção da corporação.

\section{MÉTODO}

Para atingir os objetivos desta pesquisa, o método utilizado foi a realização do direcionamento de um questionário aplicado de forma online à profissionais de vários segmentos e de formação, que preferencialmente possuem colaboradores terceirizados, e possuem em suas dependências prestadores autônomos classificados como pessoas jurídicas e que prestam serviços part-time ou full-time.

Devido ao cenário exposto, obteve-se um panorama de como essas contratações se dão sem que haja uma preocupação das partes envolvidas em seguir com diretrizes e normas pertinentes, o que propícia a corporação ficar exposta a sanções da Lei, processos trabalhistas e ações penais por parte dos prestadores e pessoas jurídicas.

O questionário foi intitulado como "Mão-de-Obra de Prestadores de Serviços Terceirizados e seus impactos Judicial - Processos Trabalhistas", em seu conteúdo são abordadas questões: que consente participar da pesquisa nos termos descritos; de identificação dos participantes; referente a caracterização da empresa onde atua; sobre Segurança do Trabalho; sobre Saúde Ocupacional; de ética e de Gestão/Administração.

Essas questões permitiram, a cada participante, afirmar em respostas diretas de sim ou não, quanto às formas de contratação, comportamentos, exigências, maneiras de tratamento, legislação, direitos, deveres, responsabilidades, aspectos jurídicos.

Ao mesmo tempo em que foram questionados quanto a demonstrar como se deram essas contratações, cada um desses questionamentos servia como alerta para que ficassem atentos aos devidos cuidados para uma possível nova contratação ou até mesmo a revisão do contrato atual entre as partes.

Com essa forma intuitiva, deu para se observar que cada um dos participantes ampliou o conhecimento e a ciência de que os trabalhadores terceirizados e pessoa jurídica devem ser tratados com os mesmos cuidados, até então dispendidos somente aos 


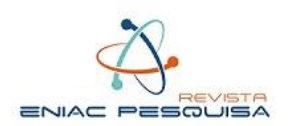

trabalhadores em regime CLT, além de estarem até mais expostos aos aspectos jurídicos em caso de acidentes ou doenças ocupacionais.

\section{DISCUSSÃO E RESULTADOS}

O propósito desta pesquisa se dá por meio exploratória com formulário eletrônico para captação de dados, e posterior descritiva e explicativa das respostas para estes ambientes que possuem em seu quadro de colaboradores, prestadores de serviços classificados para fazerem serviços pontuais ou integrado em seu quadro como CNPJ. Apenas um dos participantes afirmou não possuir mão-de-obra terceirizada em sua organização.

A metodologia utilizada foi um questionário aplicado de forma online, direcionado a profissionais de vários segmentos e formação, sendo respondido por 31 pessoas. $\mathrm{O}$ questionário abrange questões de tópicos diversos, dentre eles: Segurança e Saúde Ocupacional, Ética e Gestão/ Administração.

Nos gráficos apresentados pelas figuras abaixo apresentam as respostas obtidas com o Google Forms, onde prioriza apresentar as questões objetivas utilizadas para análise deste estudo. Após a identificação e aceite em seguir ao questionário, foram extraídos dados considerados relevantes às análises por grupos de perguntas.

Na Figura 1, tem-se as características profissionais e ramo de atividades dos participantes, através dos questionamentos diretos: a) Qual a sua área de formação?; b) Qual a área de atuação principal da empresa?; c) Porte da Empresa. É possível observar pelas respostas que há uma heterogeneidade dos participantes, ramos de atuação e portes das empresas. 
Figura 1 - Características profissionais.

(a)

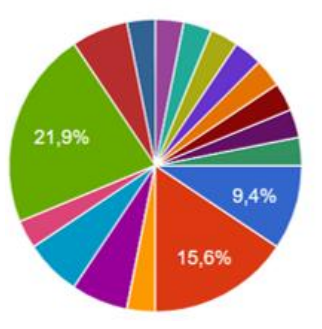

(b)

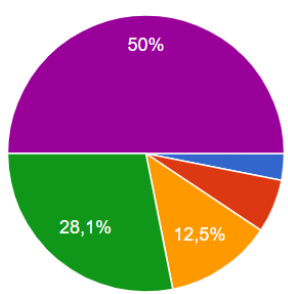

Engenharia Civil
Engenharia Elétrica
Engenharia Mecânica
Engenharia Química
Engenharia Ambiental
Engenharia de Produçăo
Engenharia Mecatrônica
Técnico em Segurança do Trabalho
A $1 / 3$

Administraçăo

- Engenheiro de Segurança do Trabalho

- Publicitária

Matematica

- Enfermeiro

A melhor profissão professora.

Tecnologia em manutenção

- Auxiliar de laboratório
$\Delta 1 / 3 \boldsymbol{\nabla}$

Fonte: Dados da pesquisa.

$$
\begin{aligned}
& \text { Empresário Individual (Eireli) } \\
& \text { Eicroempresa } \\
& \text { Empresa de Pequeno Porte } \\
& \text { Empresa de Médio Porte } \\
& \text { Empresa de Grande Porte }
\end{aligned}
$$

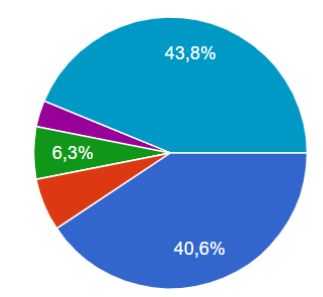

(c)

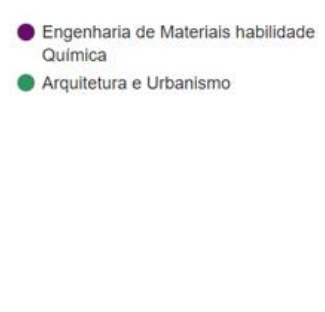

- Engenharia de Materiais habilidade

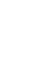


Figura 2 - Gestão da empresa e contratação de terceiros.

(a)

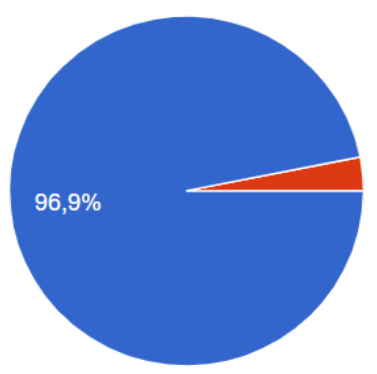

(c)

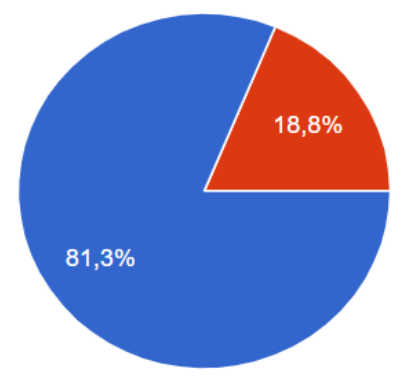

(e)

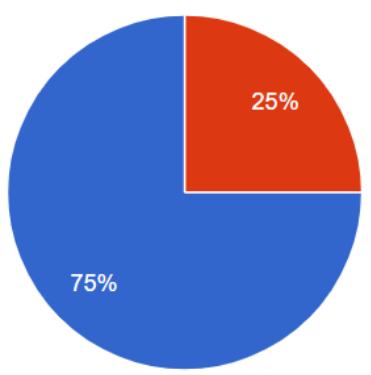

Fonte: Dados da pesquisa. (b)

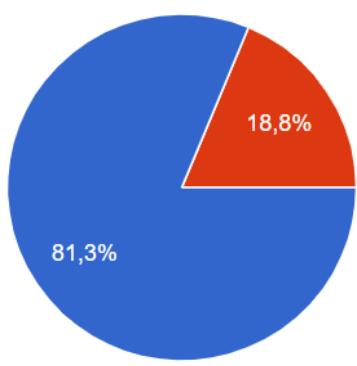

(d)

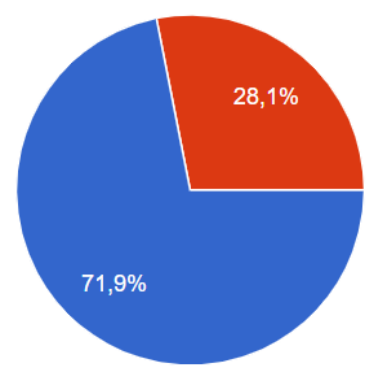

(f)

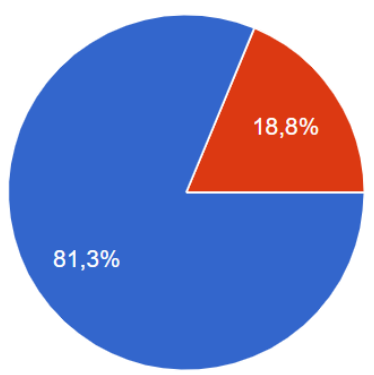

sim

Não

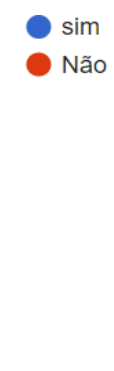

sim

Não

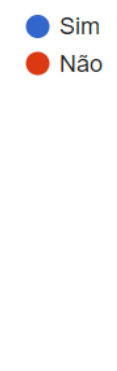

sim

Não

sim

Não

Na Figura 3, são apresentadas as perguntas sobre acidentes com prestadores de serviços terceirizados, conforme: a) Já houve acidente de trabalho com Prestadores de Serviços na unidade?; b) O motivo do acidente foi fator comportamental? e c) A empresa contratante interveio diretamente junto ao acidentado?. Evidencia-se o percentual de empresas em que já ocorreu acidentes com prestadores de serviços terceirizados, e se foi dispendida a intervenção necessária, mas há uma certa resistência em verificar os critérios de contratação dos prestadores nos serviços futuros. 


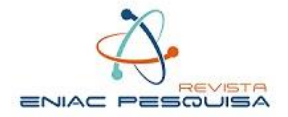

Figura 3 - Acidentes com prestadores de serviços terceirizados.

(a)
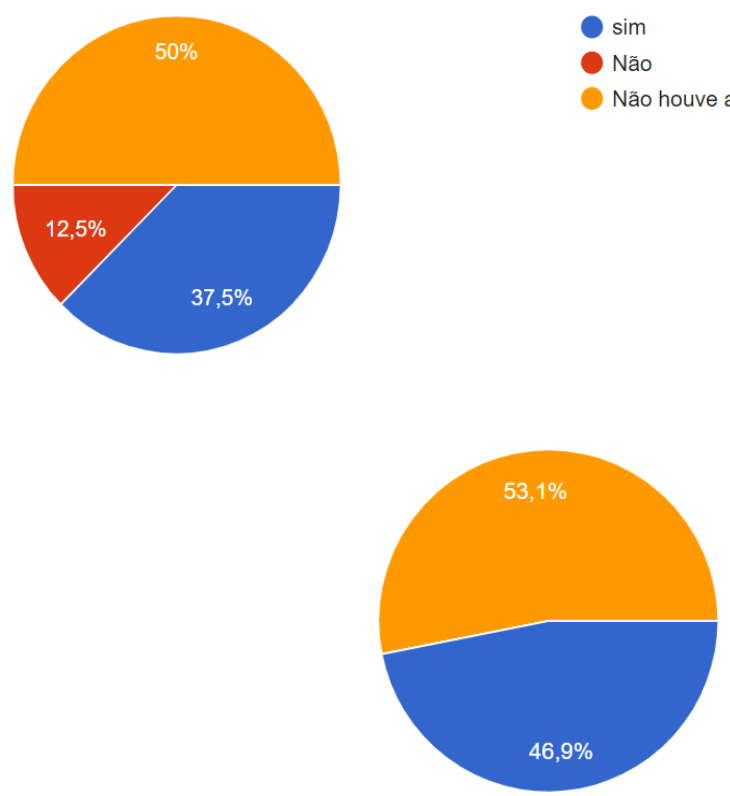

(b)

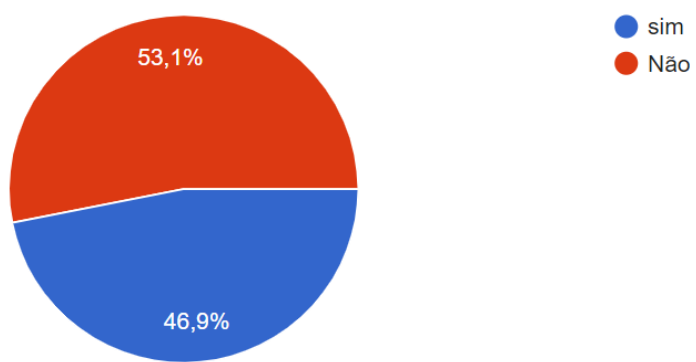

$\operatorname{sim}$

Não

(c)

Fonte: Dados da pesquisa.

Na Figura 4, são efetuadas as perguntas sobre o controle médico dos prestadores de serviços terceirizados, conforme: a) Faz parte do cronograma de integração a abordagem a temas relacionados doenças psicossomáticas?; b) A empresa faz o controle médico ocupacional de seus empregados de forma adequada, com levantamentos e exames compatíveis aos riscos a que estão exposto e devidamente elencados no PCMSO - Programa de Controle Médico de Saúde Ocupacional conforme NR-07?; c) Na ausência de cuidados profissionais no local, a unidade mantém uma equipe de socorristas treinados e material de primeiros-socorros para proporcionar um tratamento inicial?; d) Todos os acidentes com afastamento e doenças são geridos com o objetivo de devolver o indivíduo para o trabalho quando fisicamente capaz?. Analisando os resultados, pode-se observar que o controle médico fica a desejar. Essa situação é esperada, pois a contratação de terceiros remonta a ideia de economia dos custos normais com os colaboradores diretos, visto que os terceiros devem ou deveriam arcar com seu controle médico. Todavia, mesmo assim, o contratante deve verificar e manter o controle desses prestadores de serviços terceirizados. Já quanto aos primeirossocorros, observa-se uma adesão maior. 


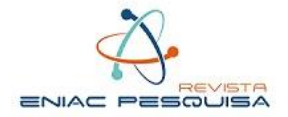

Figura 4 - Controle médico dos prestadores de serviços terceirizados

(a)

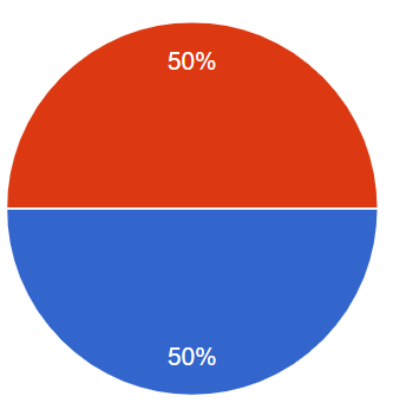

(c)

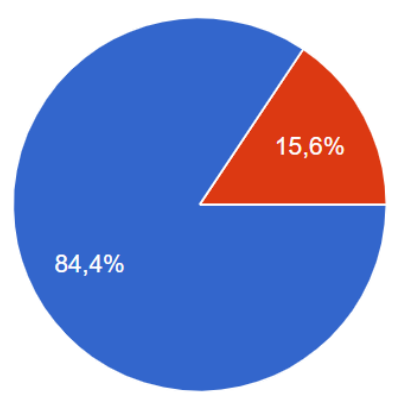

Fonte: Dados da pesquisa. (b)
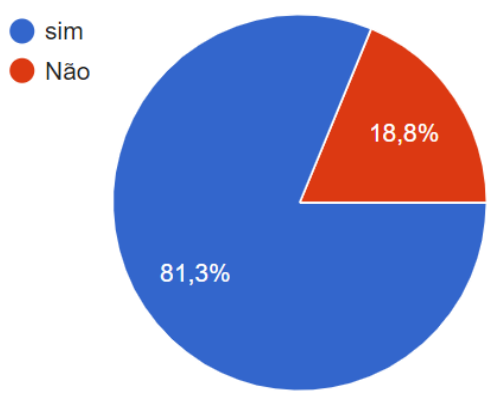

(d)

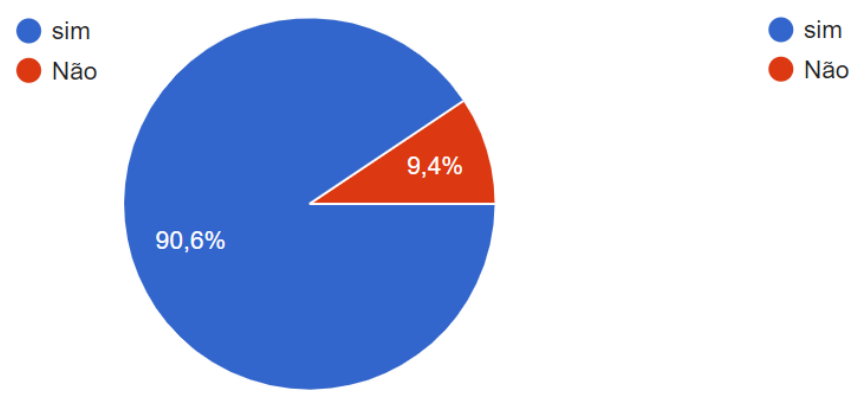

Já na Figura 5, tem-se os questionamentos inerentes à ética e de índice de satisfação, que vem sendo uma prática cada vez mais presente nas corporações, mas ainda carecem de ferramentas de denúncias, sobretudo garantindo o anonimato do denunciante. As perguntas foram: a) Durante a integração são abordados assuntos pertinentes assédio ou abuso sexual, castigo corporal, mental ou coerção física, abuso verbal ou intimidação que ocorrem na instalação ou ainda práticas de discriminação por motivos de raça, cor, sexo, idade, orientação sexual, etnia, deficiência, gravidez, religião, filiação política, filiação sindical ou estado civil?; b) Os funcionários estão satisfeitos em trabalhar na função que ocupa?; c) Há canal de denúncia implantado na empresa? 


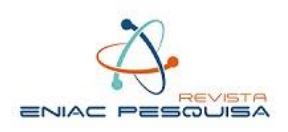

Figura 5 - Ética e pesquisa de satisfação dos serviços de terceiros

(a)

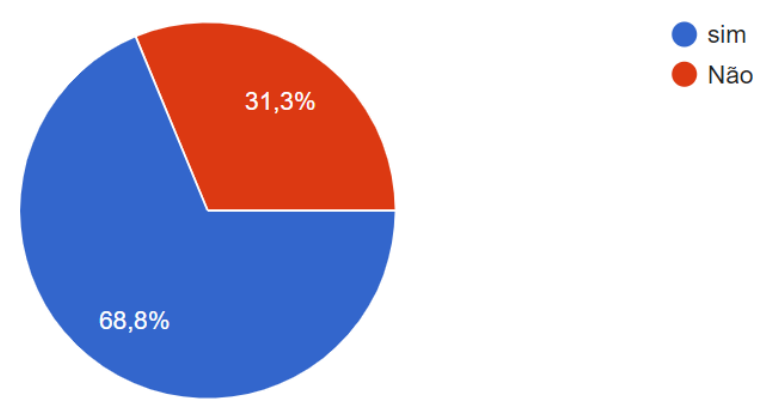

(b)

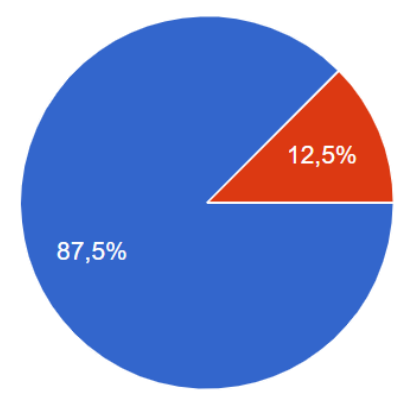

Fonte: Dados da pesquisa. (c)

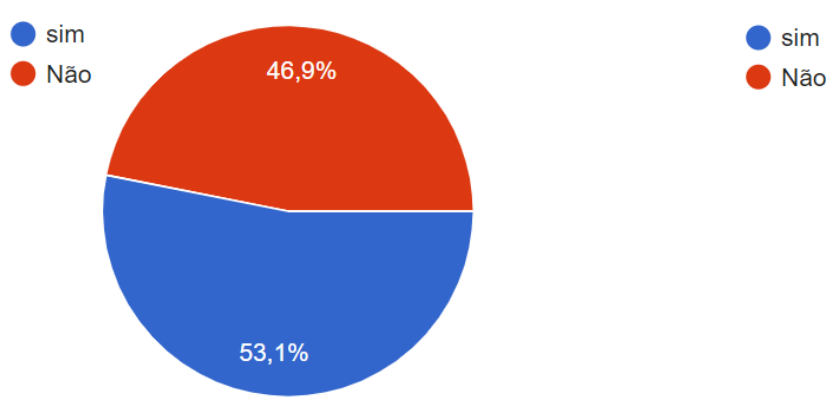

Na Figura 6, temos a gestão de documentos, normas e treinamentos dos prestadores de serviços terceirizados. As questões foram: a) A empresa possui controle dos documentos dos Prestadores de Serviços Terceirizados?; b) A gestão participa de programas de segurança e saúde ocupacional?; c) A gestão segue os procedimentos e normas da segurança e saúde ocupacional?; d) Os gestores recebem formação ou educação sobre medidas disciplinares apropriadas?.

Pode-se evidenciar que os resultados demonstram o entendimento de que a gestão é e deve ser atuante e plenamente participante do processo de contratação, de atenção e de exemplo nas atitudes e nos procedimentos relativos à segurança e saúde ocupacional. 
Figura 6 - Ética e pesquisa de satisfação dos serviços de terceiros

(a)

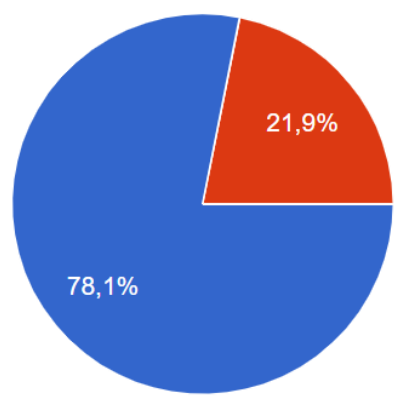

(c)

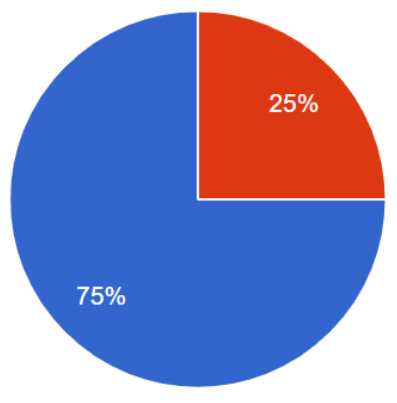

Fonte: Dados da pesquisa. (b)
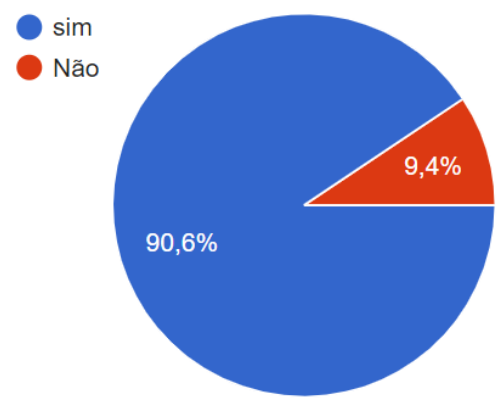

(d)

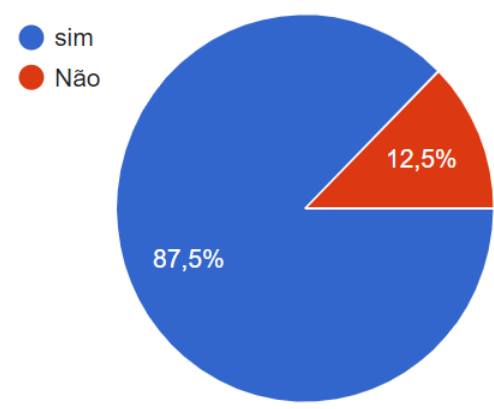

$\operatorname{sim}$

Não

Já na Figura 7, obtem-se a visão do contratante frente ao fator preço, qualidade, atendimento e tranquilidade jurídica nos serviços prestado pelo terceirizado. As perguntas foram: a) O Fator preço determina a contratação do Prestador de Serviço Terceirizado?; b) Fatores como: Atendimento a Leis, Normas e Procedimentos com relação a Saúde e Segurança do Trabalho, são levados em conta para firmar o contrato com os Prestadores de Serviço Terceirizados?; c) Existe integração do solicitante do serviço junto Setor de Compras e do SESMT da empresa, para saber o que se aplica a esse Prestador de Serviço Terceiro que será contratado?; d) Existe integração do RH, setor jurídico e SESMT junto a gestão da empresa?; e) Na sua opinião as normas e Procedimentos devidamente praticadas na empresa eliminam a possibilidade de processos trabalhistas?; f) Você considera eficaz que a prática de disseminar a cultura prevencionista, serve como como modo de inibir o trabalhador de entrar com processo trabalhista?.

Observa-se que é visível a preocupação com os valores mais acessíveis para contratar o profissional terceirizado, mas devendo-se levar em conta o cumprimento dos requisitos mínimos necessários para o desenvolvimento adequado das atividades com o cumprimento 
das leis. Fato esse que é determinante na busca da tranquilidade em não estar vulnerável à possíveis processos jurídicos.

Figura 7 - Fator preço, qualidade, atendimento, tranquilidade jurídica na contratação dos serviços terceirizados

(a)

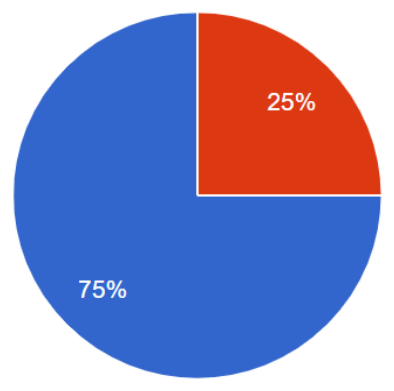

(c)

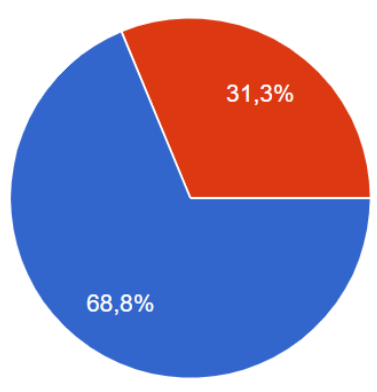

(e)

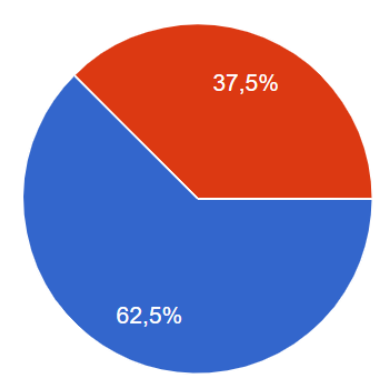

Fonte: Autor. (b)

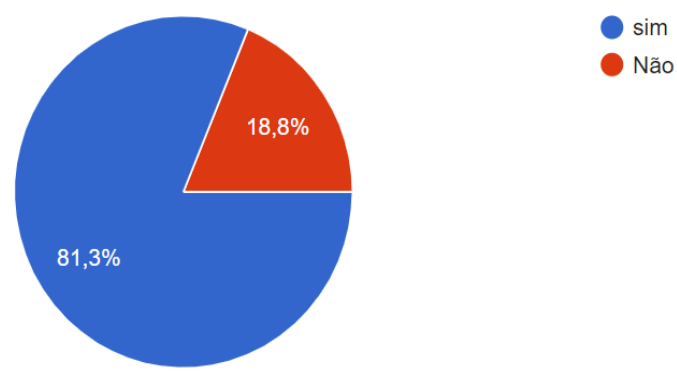

(d)

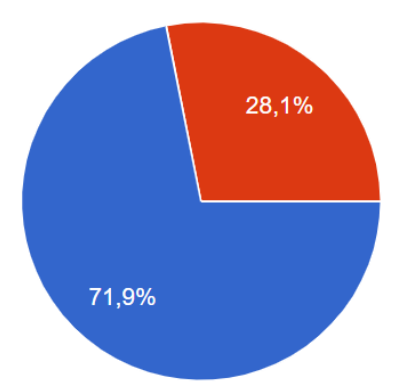

(f)
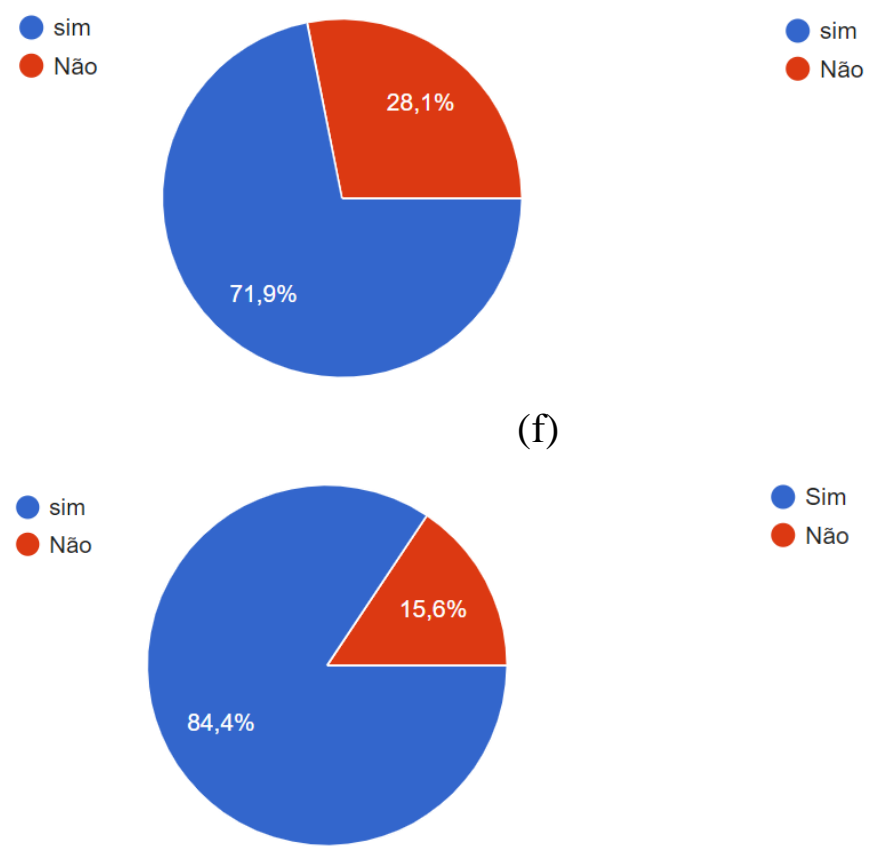

\section{CONSIDERAÇÕES FINAIS}

Com o levantamento de dados obtidos junto aos empregadores, foi possível observar que as contratações de serviços terceirizados possuem cunho de agilidade da contratação, de modo a resolver alguma necessidade urgente. Dessa forma, não há a real concepção dos 


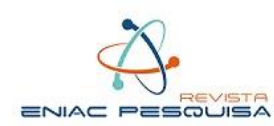

riscos que possam implicar em caso de ocorrência de acidente ou doença do trabalho com esse contratado, quer seja através de agência de terceirização ou contratação direta desse prestador sem vínculo em regime CLT.

Nesse artigo é plausível afirmar a importância da Segurança do Trabalho, Ética e questões Cíveis, Criminal e a exposição em possíveis Processos Trabalhistas por parte das corporações, pois a excelência não é algo que se consiga atingir sem ter uma equipe multidisciplinar envolvida no processo e devidamente integrada à alta direção da empresa, desde que ela também compactue desses objetivos. Sendo assim, os princípios prevencionistas atuantes na cultura da empresa, revela uma estrutura preocupada em garantir um ambiente de trabalho que propicie segurança, saúde de todas as pessoas na corporação, sejam elas direta ou indiretamente "Prestadores de Serviço" ligados à corporação.

Conclui-se assim, que é tangível uma corporação ter uma solidez referente a extinção de processos trabalhistas, desde que ela possibilite condições indistintas de trabalho aos profissionais envolvidos ao processo prevencionista e desenvolvam um ambiente que garantam a segurança e saúde dos trabalhadores.

Um fator que colabora para perpetuar o cenário atual, é a ineficiência de fiscalizações dos órgãos públicos nas corporações, onde garante um salvo conduto para ilegalidade por parte dos envolvidos, o que deveria funcionar como um ato prevencionista aos possíveis agentes existentes no ambiente, passa a ser abordado somente quando um acidente de proporções impactantes ocorre ao colaborador/ prestador e a comunidade.

Esses padrões nos levam a visualizar o formato mais comum de gestão existente nas corporações referente a segurança e saúde do trabalho predominantemente predatório na sociedade, devendo ainda ser amplamente abordados os fatores extremante prejudiciais, tais como adoecimento laboral causado, por fatores psicossociais, questões discriminatórias e excesso de trabalho que passa a ser intitulado como "assédio moral" e o resultado do impacto não está centralizado somente aos empresários, mas sim, a toda cadeia envolvida repercussões inclusive na esfera judicial e trabalhista.

\section{REFERÊNCIAS}

Carvalho, J. R. de J. M. (2015). Terceirização: espécies, causas políticas e econômicas e aspectos legais.

Disponível em: 
https://www.direitonet.com.br/artigos/exibir/9542/Terceirizacao-especies-causaspoliticas-eeconomicas-e-aspectos-legais Acesso em: 17/10/2020.

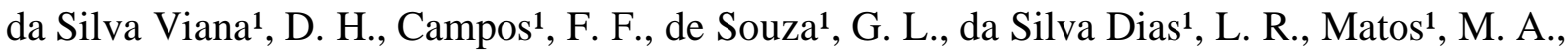
Manica, E., \& de Lima Ferreira, F. Gestão de operações e serviços para aumento da eficiência da prestação de serviços na era da terceirização. Disponível em: http://semanaacademica.org.br/system/files/artigos/artigo_pi_grupo_2_rev.pdf Acesso em: $14 / 10 / 2020$

Decreto-Lei no 5.452, de 1 de maio de 1943 (1943). Aprova a Consolidação das Leis do Trabalho. Disponível em: http://www.planalto.gov.br/ccivil_03/decreto-lei/del5452.htm Acesso em: 17/10/2020.

Lei $\mathrm{n}^{\text {o }}$ 8.213, de 24 de julho de 1991 (1991). Dispõe sobre os Planos de Benefícios da Previdência Social e dá outras providências. Brasília, DF. Disponível em: http://www.planalto.gov.br/ccivil_03/leis/18213cons.htm Acesso em: 17/10/2020.

Lei 13.467-2017, de 13 de julho de 2017 (2017). Altera a Consolidação das Leis do Trabalho (CLT), aprovada pelo Decreto-Lei no 5.452, de 1o de maio de 1943, e as Leis nos 6.019, de 3 de janeiro de 1974, 8.036, de 11 de maio de 1990, e 8.212, de 24 de julho de1991, a fim de adequar a legislação às novas relações de trabalho. Brasília, DF. Disponível em: http://www.planalto.gov.br/ccivil_03/_ato2015-2018/2017/lei/L13467.htm Acesso em: $17 / 10 / 2020$.

Mendes, R., \& Campos, A. C. C. (2004). Saúde e segurança no trabalho informal: desafios e oportunidades para a indústria brasileira. Revista Brasileira de Medicina do Trabalho, 2(3), 209-223. Disponível em: http://renastonline.ensp.fiocruz.br/sites/default/files/arquivos/recursos/SST_no_trabalho_infor mal.pdf Acesso em: 14/02/2021

Nascimento, A. M. (2002). Iniciação ao direito do trabalho. rev. e atual. São Paulo: $L T r, 2$.

NR-1, de 09 de março de 2020 (2020). Disposições gerais e gerenciamento de riscos ocupacionais. Brasília, DF. Disponível em: https://sit.trabalho.gov.br/portal/images/SST/SST_normas_regulamentadoras/NR-01atualizada-2020.pdf Acesso em: 17/10/2020.

NR-5, de 30 de julho de 2019 (2019). Comissão Interna de Prevenção de Acidentes. Brasília, DF. Disponível em: https://sit.trabalho.gov.br/portal/images/SST/SST_normas_regulamentadoras/NR-05.pdf Acesso em: 17/10/2020.

NR-7, de 9 de março de 2020 (2020). Programa de Controle Médico de Saúde Ocupacional, DF. em: https://sit.trabalho.gov.br/portal/images/SST/SST_normas_regulamentadoras/NR-07atualizada-2020.pdf . Acesso em: 17/10/2020. 
NR-9, de 10 de março de 2020 (2020). Avaliação e controle das exposições ocupacionais a agentes físicos, químicos e biológicos. Brasília, DF. Disponível em: https://sit.trabalho.gov.br/portal/images/SST/SST_normas_regulamentadoras/NR-09atualizada-2020.pdf Acesso em: 17/10/2020.

Portaria n 3.214 , de 8 de junho de 1978 (1978). Aprova as Normas Regulamentadoras - NR do Capítulo V, Título II, da Consolidação das Leis do Trabalho, relativas a Segurança e Medicina do Trabalho. Brasília, DF. Disponível em: https://www.camara.leg.br/proposicoesWeb/prop_mostrarintegra;jsessionid=9CFA236F7343 3A3AA30822052EF011F8.proposicoesWebExterno1? codteor $=309173 \&$ filename $=$ Legislacao Citada+-INC+5298/2005 Acesso em: 17/10/2020.

Portaria $n^{\circ}$ 6.730, de 9 de março de 2020 (2020). Aprova a nova redação da Norma Regulamentadora $\mathrm{n}^{\circ} 01$ - Disposições Gerais e Gerenciamento de Riscos Ocupacionais. (Processo $\mathrm{n}^{\mathrm{o}}$ 19966.100073/2020-72). Disponível em: https://www.in.gov.br/en/web/dou//portaria-n-6.730-de-9-de-marco-de-2020-247538988 Acesso em: 17/10/2020.

Portaria da Secretaria de Inspeção do Trabalho no 247, de 12 de junho de 2011 (2011). Altera a Norma Regulamentadora $\mathrm{n}^{\circ} 5 . \quad$ Disponível em: http://www.normaslegais.com.br/legislacao/portariasit247_2011.htm Acesso em: 17/10/2020.

Portaria SSST no 8, de 8 de maio de 1996 (1996). Altera a Norma Regulamentadora NR-7Programa de Controle Médico de Saúde Ocupacional-PCMSO. Brasília, DF. Disponível em: https://www.legisweb.com.br/legislacao/?id=181462 Acesso em: 17/10/2020.

Reis, J. T. (2009). Relações de trabalho: estágio de estudantes. Juruá Editora. 